\title{
MESOCLIMAS DO MUNICÍPIO DE PRATA (MG)
}

\author{
NOVAIS, Giuliano Tostes - giuliano.novais@ueg.br \\ Universidade Estadual de Goiás / UEG
}

Submetido em: 29/04/2020

Aceito para publicação em: 05/01/2021

Publicado em: 06/04/2021

DOI: http://dx.doi.org/10.5380/abclima.v28i0.73300

\begin{abstract}
RESUMO: A classificação climática é fundamental para o planejamento ambiental e econômico, determinando o clima em diversas regiões do nosso planeta. Este trabalho sugere uma nova abordagem de mapeamento das unidades climáticas para o município de Prata (MG), analisando a temperatura média do mês mais frio (TMMMF), a quantidade de meses secos, a influência de sistemas atmosféricos e suas implicações na quantidade de chuva, e nas passagens de frentes frias com possibilidade de formação de geadas. A hierarquia desse Sistema de Classificação Climática é dividida em Climas Zonais,Domínios, Subdomínios, Tipos, Subtipos e Mesoclimas. Para delimitar as unidades climáticas foram utilizados dados de postos de coleta de precipitação pluviométrica da Agência Nacional de Águas (ANA) e do Instituto Nacional de Meteorologia (INMET). A definição das unidades climáticas, em nível municipal, gera novas contribuições para estudos regionais em Climatologia de Detalhe. Esse novo sistema classificatório do clima é mais aperfeiçoado, devido ao amplo número de dados históricos disponibilizados na internet, e pode ser usado em diagnósticos ambientais, materiais didáticos e análises agrícolas.
\end{abstract}

PALAVRAS-ChAVE: Unidades Climáticas; Temperatura Média do Mês mais Frio; Precipitação Pluviométrica; Quantidade de meses secos; Climatologia de Detalhe.

\section{MESOCLIMATES OF THE MUNICIPALITY OF PRATA (MINAS GERAIS)}

ABSTRACT: The climatic classification is fundamental for the environmental and economic planning, determining the climate in several regions of our planet. This work suggests a new approach to mapping climatic units for the municipality of Prata (Minas Gerais), analyzing the average temperature of the coldest month (TMMMF), the number of dry months, the influence of atmospheric systems and their implications on the amount of rain, and in the passages of cold fronts with the possibility of frost formation. The hierarchy of this Climate Classification System is divided into Zone Climates, Domains, Subdomains, Types, Subtypes and Mesoclimates. To delimit the climatic units, data were collected from rainfall collection points of the National Water Agency (ANA) and the National Meteorological Institute (INMET). The definition of climatic units at the municipal level generates new contributions to regional studies in Detail Climatology. This new climate classification system is further improved, due to the large number of historical data available on the internet, and can be used in environmental diagnostics, teaching materials and agricultural analyzes

KEYWORDS: Climatic Units; Average Temperature of the Coldest Month; Rainfall Precipitation; Number of Dry Months; Climatology of Detail.

\section{INTRODUÇÃO}

A Climatologia na atualidade dispõe de muitos recursos tecnológicos para a compreensão das características climáticas nos vários lugares do Globo. O uso de satélites e estações meteorológicas, que medem as condições do tempo, nos auxiliam no entendimento dos sistemas classificatórios do clima. Para Pimenta (2019), o desenvolvimento de novas tecnologias permitiu mudanças em diversas áreas e setores da sociedade, principalmente no acesso a informação e 
comunicação, facilitando sobretudo a difusão de dados meteorológicos e climatológicos.

Segundo Vianello (1986) as condições gerais do tempo meteorológico atuantes em uma região estão relacionadas aos mecanismos da escala global da atmosfera. Para isso, o entendimento da dinâmica atmosférica sobre uma área deve começar com uma visão mais ampla. Conforme Cavalcanti (2009), a Climatologia indica a média das condições do tempo meteorológico no período de algumas décadas, sendo que os sistemas de tempo provocam a variabilidade que observamos e que afetam as atividades humanas.

A relevância dos sistemas de classificação climática se deve ao fato que é concebível investigar e determinar os climas de diferentes locais levando em consideração elementos climáticos diversos ao mesmo tempo, melhorando a troca de informações e estudos posteriores para diferentes decisões (NÓBREGA, 2010).

Os sistemas de classificação climática utilizados na atualidade, em sua maioria, abordam o clima de forma geral. Na época que surgiram essas classificações os seus autores não dispunham de toda a tecnologia que utilizamos nos dias de hoje, como softwares de SIG, estatísticas e dados de reanálise por exemplo, por isso, os mesmos devem ser respeitados.

De acordo com Sampaio et al (2011), Strahler inventou uma classificação genética do clima baseada na formação dos regimes das massas de ar e nos elementos de precipitação e temperatura. Köppen classifica os climas baseado na temperatura e na precipitação (modelo analítico), sendo ajustados pela distribuição da vegetação. Em 1961 Geiger ajustou o sistema classificatório de Köppen e o tornou o mais empregado em trabalhos científicos e em livros didáticos. Outra classificação muito utilizada, principalmente em aplicações agrícolas é a de Thornthwaite (1948), que introduziu o conceito de evapotranspiração potencial (ETP), de grande relevância para a Climatologia e Agronomia. Comparando dados de precipitação e ETP, foram calculados vários tipos índices que compõe o balanço hídrico.

Um dos grandes nomes da classificação climática brasileira foi Nimer, que em 1972 elaborou um sistema utilizado até hoje pelo Instituto Brasileiro de Geografia e Estatística (IBGE), ele delimitou o clima de uma forma quantitativa, utilizando a precipitação e a temperatura, mas também tem um método qualitativo, considerando a quantidade de meses secos e a circulação atmosférica. Também no Brasil, Monteiro (1973) criou um sistema classificatório do clima abrangendo escalas locais e regionais, que busca um melhor entendimento da variabilidade local, caracterizado pela influência de fatores geográficos e aborda uma análise rítmica das condições do tempo atmosférico.

Algumas publicações atuais estão promovendo novos métodos de classificação climática, como o mapeamento bioclimático do Estado do Rio de Janeiro (CRONEMBERGER et al, 2011), a articulação de diferentes níveis escalares do clima de Jardim et al (2019), e na criação de unidades climáticas de Tarifa \& Azevedo (2001), e Silva \& Jardim (2019).

Novais (2019) criou um sistema que classifica os climas a partir da grande quantidade de dados de reanálise disponíveis e também por modelagem, ajustando os limites das unidades climáticas de acordo com a escala climática adotada. O detalhamento das unidades climáticas feito por Novais, fornece 
subsídios para novos estudos regionais dentro da Climatologia Aplicada, apresentando dados de forma mais didática para o ensino e aprendizagem dessa ciência. Esse sistema auxilia também em atividades antrópicas que visam um melhor planejamento das condições ambientais de cada localidade estudada.

As Escalas Superiores do Clima estão próximas do nível planetário e modificam a atmosfera numa escala inferior. Dentro dessa escala estão os climas zonais e regionais.

O clima zonal é regulado principalmente pela radiação solar, que aquece e esfria a superfície terrestre. A inclinação dos raios do Sol depende da latitude do local, e é diretamente associada à altura solar sazonal. Possui alguns fatores geográficos de grande influência como: a latitude, a grande diferença de altitude, a continentalidade e a maritimidade.

Para Jesus (2008), o clima regional tem uma maior influência dos fatores geográficos controladores do clima, por se tratar de uma escala de transição entre o nível superior para o inferior. Dentre aqueles de maior relevância podemos mencionar: a orientação e a disposição dos grandes conjuntos orográficos; as interferências das correntes oceânicas; as condições topográficas predominantes; o maior ou menor grau de influência da maritimidade e da continentalidade; a posição latitudinal e a exposição da região, dentre muitos outros fatores estáticos. $O$ autor também destaca os fatores de ordem dinâmica da natureza:

\begin{abstract}
Em consonância aos fatores de natureza geográfica, os de natureza dinâmica também se estruturam num sistema de circulação atmosférica secundária, representada por um conjunto de perturbações sinóticas que passam a atuar em diferentes épocas do ano. Essas correntes secundárias são resultantes da instalação de pequenos centros de ação (núcleos ciclônicos e anticiclônicos), que atuam na dinâmica do tempo e do clima regional ao longo do ano (Jesus, 2008, p. 178).
\end{abstract}

Portanto, no clima regional, é importante considerar as variações anuais, sazonais e mensais dos elementos climáticos, assim como a análise dos sistemas de circulação atmosférica atuantes e os tipos de tempo que assumem grande significação. É necessário também, nesse nível (clima regional), conhecer a situação sinótica da atmosfera regional a fim de se definir a posição dos centros de ação atuantes (JESUS, 2008).

As Escalas Inferiores do Clima estão próximas dos indivíduos habitantes da superfície e são influenciados pela atmosfera da escala superior. Nessa escala climática estão o clima sub-regional, clima local, topoclima e microclima.

O clima sub-regional é controlado pela geomorfologia do local, que produz interferências no fluxo energético ou mesmo na circulação secundária. Feições geográficas e antrópicas afetam diretamente o clima local, que precisa de dados mais precisos (como os que são adquiridos em estações meteorológicas) mostrando a variabilidade e a tendência de elementos climáticos. O clima urbano e o mesoclima estão inseridos nessa categoria.

A paisagem provoca um grande efeito no topoclima. Este pode ser influenciado por um aquecimento desigual de vertentes, ou pela presença de escarpas abruptas, típicas de um relevo acidentado. O microclima é a menor 
escala climática e abrange locais específicos de uso e cobertura do solo diferenciados.

O produto derivado de um sistema de relações e transformações do meio físico com a atmosfera, sintetizando as condições do meio é chamado de unidade climática. Conforme Milanesi (2016), ela sintetiza a dinâmica climática de um lugar, identificando-Ihe no tempo e no espaço o ritmo de variação de seus atributos dando-Ihe uma feição climática. Para Jardim (2015), ao se pensar a definição de unidades climáticas, não se trata apenas de espacializar a variação de determinado elemento atmosférico no tempo e no espaço, mas pensa-lo de forma integrada aos demais elementos do clima e componentes do meio e nas características do produto resultante dessa influência recíproca. Portanto, a unidade climática expressa a menor compartimentação de uma hierarquia climática, e para isso, depende da utilização adequada de uma escala climática.

Armond et al (2016) afirmam que a complexidade do mundo e a necessidade de uma abordagem híbrida dos fenômenos nos desafiam a uma compreensão e uma realização de classificações que concebam a relação sociedade e natureza como uma unidade contraditória, porém, complementar. Nos desafiam, também, a explorar as formas de representação cartográfica para que se possa, para além de uma dimensão teórica, conceitual e de método, avançar nas linguagens geográficas de abordagem do fenômeno climático. Portanto, do ponto de vista analítico, acreditamos que este trabalho possa superar uma lacuna ainda existente nos sistemas classificatórios do clima, que é a atualidade de modelos para serem aplicados.

O município de Prata é o maior em extensão do Triângulo Mineiro, situado no centro geográfico da região. Possui $4.848 \mathrm{~km}^{2}$ e uma população de 27.856 habitantes (Estimativa IBGE, 2019). É ligado pelas rodovias federais BR153, 262 e 497 ao restante do estado e ao país. De acordo com Novais (2013), o município tem a pecuária como principal atividade econômica, detém um dos maiores rebanhos bovinos do estado de Minas Gerais; além da importância de sua bacia leiteira, o cultivo de grãos está em fase de contínuo crescimento. Os mais importantes produtos agrícolas cultivados no município são o milho, a soja, a cana-de-açúcar, a laranja e o feijão. Destacam-se ainda áreas consideráveis destinadas a silvicultura para aproveitamento industrial da madeira, da Souza Cruz Florestal e da Faber-Castell.

\section{MATERIAL E MÉTODOS}

Por possibilitar a delimitação de unidades climáticas para uma pequena área (grande escala cartográfica), abrangendo a Climatologia de Detalhe, o Sistema de Classificação Climática a ser aplicado no município de Prata (MG) foi baseado na classificação adotada por Novais (2019), que em sua tese utilizou-o para o Bioma Cerrado no Brasil. Essa classificação propõe um modelo que possui contribuições dos modelos clássicos, mesclando o empírico e o genético, juntamente com a influência de outros parâmetros climáticos como o controle astronômico, temperatura mínima do mês mais frio e a atuação do relevo (geomorfologia). É uma associação de informações, para gerar um padrão que aborda tanto os valores observados do tempo e do clima, quanto a influência dos sistemas meteorológicos. 
A cartografia climática tem resolução espacial de $0,01^{\circ}$ (ou $1 \mathrm{~km}$ ), fornecendo uma representação mais precisa de regiões heterogêneas, com a combinação de dados climáticos oriundos de várias fontes independentes, reanalisando dezenas de milhares de estações meteorológicas espalhadas pelo planeta Terra.

A primeira hierarquia da classificação climática adotada por esse trabalho pertence as Zonas Climáticas do Planeta, que de acordo com Novais (2017), são determinadas pela altura do Sol, formando regiões de incidência solar delimitadas por linhas imaginárias. A partir das Zonas Climáticas são criados os Climas Zonais, a segunda hierarquia da classificação climática. Os Climas Zonais são diferentes das Zonas Climáticas, pois sua delimitação é baseada na temperatura média do mês mais frio (TMMMF). A distribuição de energia ocasionada pela radiação solar na troposfera se diferencia latitudinalmente, tornando a temperatura o principal elemento climático nessa escala. Os limites específicos de cada Clima Zonal não são absolutos, mas servem para estabelecer uma terminologia conveniente que seja útil. As duas hierarquias fazem parte da escala superior do clima, juntamente com os Domínios Climáticos.

Os Domínios Climáticos fazem parte da terceira hierarquia climática. Os mesmos podem pertencer a mais de um Clima Zonal. A TMMMF é de suma importância na sua caracterização, mas também são controlados por sistemas meteorológicos como zonas de convergência de ventos e umidade, atuação de anticiclones, frentes frias e a possibilidade de formação de geada. Como exemplos de interações desses sistemas na formação dos domínios climáticos temos a Zona de Convergência Intertropical (ZCIT) e a Alta Polar Sul (APS). O primeiro predomina na estação de outono no norte do Brasil, provocando uma maior quantidade de chuva, que define o domínio Equatorial. Já o segundo, ocorre na porção meridional do país, e caracteriza o domínio climático Subtropical.

De acordo com Jesus (2008), na escala climática regional, é importante considerar as mudanças mensais dos elementos climáticos, como é o caso do campo higrométrico responsável pela entrada de água no sistema do clima. Deste modo, os Domínios são divididos em Subdomínios Climáticos, com critério de duração dos meses secos, podendo variar de: úmido (0 a 3 meses secos); semiúmido (4 a 5 meses secos); semisseco (6 a 7 meses secos); e seco (8 a 11 meses secos).

Segundo Novais (2019), a metodologia para determinação de mês seco consiste na diferença entre a precipitação pluviométrica e a evapotranspiração potencial (ETP). Se a precipitação for menor que a ETP, o mês é seco. De acordo com Rolim (2020), um solo nessas condições está potencialmente secando, o que mostra uma deficiência de água no sistema solo-planta-atmosfera, gerando uma restrição no crescimento das plantas e diminuindo a vazão da drenagem superficial e subsuperficial.

Para o cálculo da ETP foi utilizada a planilha de balanço hídrico climatológico elaborada por Sentelhas et al (1998), a partir do método proposto por Thornthwaite \& Mather (1955), tendo a latitude e a temperatura média como parâmetros meteorológicos. A planilha também calcula valores de excedente e déficit hídrico, para ajudar na diferenciação das unidades climáticas. 
Seguindo a hierarquia dessa classificação as próximas unidades climáticas são os Tipos, transição de uma escala climática superior para uma inferior, mostrando a localização dos Domínios e Subdomínios no território brasileiro. Nesse nível hierárquico, os fatores geográficos exercem grande influência nas condições climáticas. Por isso, são delimitados pelo relevo e pela vegetação, sendo controlados também por sistemas meteorológicos que ali atuam e modificam o tempo drasticamente. Como exemplos dessa delimitação estão o Espigão Mestre, grande conjunto orográfico que faz a divisa entre Tocantins e Bahia (Tipo Central com Nordestino); planícies litorâneas até escarpas de planalto, com influência da maritimidade (Tipo Litorâneo); a possibilidade de ocorrência de uma geada (Temperatura Mínima absoluta $<3,5^{\circ} \mathrm{C}$ ) em 30 anos é o limite para a ocorrência de um Tipo Meridional no Brasil; e o limite do bioma de Floresta Amazônica determina o Tipo Amazônico.

O Quadro 1 demonstra a proposta de unidades climáticas para o território brasileiro subdividida da segunda a quarta hierarquia (Domínios Climáticos, Subdomínios Climáticos e Tipos Climáticos).

Quadro 1 - Unidades climáticas brasileiras. Fonte: Novais (2019).

\begin{tabular}{|c|c|c|}
\hline Domínio Climático & Subdomínio Climático & Tipo Climático \\
\hline Equatorial & $\begin{array}{l}\text { Úmido } \\
\text { Semiúmido } \\
\text { Semiseco } \\
\text { Seco }\end{array}$ & $\begin{array}{l}\text { Amazônico } \\
\text { Litorâneo } \\
\text { Nordestino }\end{array}$ \\
\hline Equatorial Ameno & $\begin{array}{l}\text { Úmido } \\
\text { Semiúmido }\end{array}$ & Amazônico \\
\hline Tropical & $\begin{array}{l}\text { Úmido } \\
\text { Semiúmido } \\
\text { Semiseco } \\
\text { Seco }\end{array}$ & $\begin{array}{l}\text { Central } \\
\text { Litorâneo } \\
\text { Meridional } \\
\text { Nordestino } \\
\text { Ocidental } \\
\text { Setentrional }\end{array}$ \\
\hline Tropical Ameno & $\begin{array}{l}\text { Úmido } \\
\text { Semiúmido } \\
\text { Semiseco } \\
\text { Seco }\end{array}$ & $\begin{array}{l}\text { Central } \\
\text { Litorâneo } \\
\text { Meridional } \\
\text { Nordestino }\end{array}$ \\
\hline Subtropical & $\begin{array}{l}\text { Úmido } \\
\text { Semiúmido } \\
\text { Semiseco }\end{array}$ & $\begin{array}{l}\text { Litorâneo } \\
\text { Meridional } \\
\text { Setentrional }\end{array}$ \\
\hline Subtropical Frio & Úmido & $\begin{array}{l}\text { Meridional } \\
\text { Setentrional }\end{array}$ \\
\hline Árido & - & Nordestino \\
\hline
\end{tabular}

De acordo com Novais (2019), os Subtipos Climáticos também são delimitados por sua localização, mas em escala menor. O componente estrutural geomorfológico, fato diretamente ligado à dinâmica climática atual e pretérita, serve para demarcar essas unidades climáticas, demonstrando, claramente, o 
papel da superfície - topografia - e sua relação com os sistemas atmosféricos. Essa hierarquia pertence as escalas climáticas sub-regional e local, portanto, a unidade geomorfológica é considerada a base para sua determinação. Podem ser utilizados para análises socioambientais detalhadas, caracterização física de uma área de estudo, etc. Evidencia as características climáticas (TMMMF, meses secos, déficit e excedente hídricos) existentes nos tipos, subdomínios e domínios climáticos.

Para Ribeiro (1993), o relevo é uma das principais características fisiográficas responsáveis pela modificação da circulação regional da atmosfera, criando situações de barlavento e sotavento. Por outro lado, as diferenças de altitude tem um papel de destaque na distribuição da radiação líquida, na retenção do vapor d'água e no armazenamento de calor sensível. A atuação conjunta desses parâmetros é suficiente para provocar variações no clima regional, gerando feições dos climas locais. Novais (2019) diz que há uma relação direta entre as unidades climáticas de menor hierarquia com as unidades morfoesculturais do relevo.

Jesus (2018), enfatiza que a altitude em particular, na categoria da mesoescala, possui uma importância significativa, ou seja, um papel destacado na distribuição da radiação líquida, na retenção do vapor d'água e no armazenamento de calor sensível. Essas e outras características passam a proporcionar a formação de verdadeiros enclaves climáticos, com grandes reflexos na estrutura térmica, surgindo, assim, os chamados mesoclimas, no interior dos climas regionais. Rempp (1937) considerou como mesoclima aquele circunscrito de maneira natural ou artificial, produzido em função da posição de um vale ou declive, assinalando, assim, sua concepção sobre mesoclimas. A definição de Rempp abre para uma ampla pauta de discussões e, ao mesmo tempo, coloca a questão do aspecto relativo que deve ser considerado na análise do mesoclima no contexto da terminologia escalar do clima. Bruchmann (1999) definiu, como mesoclima, a extensão da superfície terrestre que produz uma modificação no ambiente climático, proporcionando mesoclimas de montanha e vales, dentre outros.

Nessa classificação climática, o Mesoclima não é uma ordem de grandeza intermediária entre o Macro e Microclima, e sim, a sétima hierarquia, de escala climática local, delimitados por feições geográficas ou antrópicas, de destaque na paisagem, que interferem no fluxo energético (serras, linhas de cumeada, topos de planaltos, vales abertos e encaixados, áreas de mata, zonas urbanas, etc). Brasil:

Ribeiro (1993) explica como o Topoclima é formado, dando exemplos no

O Topoclima corresponde a uma derivação do Mesoclima devido à rugosidade do terreno, que tem como consequência a energização diferenciada do terreno, durante o período diurno para as diversas faces de exposição a radiação solar. As diferenças de exposição introduzem grandes contrastes entre as vertentes numa mesma latitude e altitude. No Centro-Sul do Brasil são conhecidas as vertentes noruegas voltadas para o sul e as soalheiras, voltadas para o norte, estas muito mais valorizadas tanto para edificações como para a agricultura. Em regiões serranas essa diferença na quantidade de energia disponível é mais visível. Durante a noite, principalmente na influência de anticiclones (céu claro e ausência de ventos), a rugosidade do terreno provoca drenagem do ar frio em direção aos fundos de vale, chegando a provocar um padrão de circulação terciária. A ocorrência de geadas e 
nevoeiros no Centro-Sul do Brasil em função da drenagem e acúmulo de ar frio constituem fenômenos de natureza topoclimática (1993; p.5).

Para o município de Prata (MG) foram definidas as unidades climáticas em quase todos os níveis hierárquicos da Classificação de Novais, ou seja, Zonas Climáticas, Climas Zonais, Domínios Climáticos, Subdomínios Climáticos, Tipos Climáticos, Subtipos Climáticos e Mesoclimas. Dois subtipos climáticos foram delimitados seguindo a metodologia do artigo de Novais et al (2018), onde os mesmos determinaram as unidades climáticas do Triângulo Mineiro. Um outro subtipo foi criado a partir do mapa geomorfológico elaborado por Baccaro et al (2001), englobando a área dos relevos residuais do oeste do Triângulo Mineiro, pois esse relevo influencia na entrada e saída de água no sistema atmosférico, diminuindo a ETP, por exemplo. Foram criados 34 Mesoclimas delimitados por elementos geomorfológicos de pequenos táxons, formas de relevo de grande destaque na paisagem e também pela zona urbana.

O trabalho técnico científico realizado anteriormente como geógrafo, mapeando todo o município, foi fundamental para a elaboração desse trabalho. Todos os aspectos geográficos do Prata foram conferidos "in loco", desde os físicos aos socioeconômicos, como: hidrografia, relevo, vegetação e uso do solo, vias de circulação, distritos, povoados e comunidades rurais; sendo percorridos mais de 4 mil quilômetros de estradas e 1600 propriedades rurais. Desse mapeamento surgiu o Guia do Município - Prata, turístico e rodoviário, elaborado por Novais (2013). O guia representa toda a área municipal em 12 mapas detalhados, coloridos e elaborados em programa de desenho (AutoCad), aproveitando o georreferenciamento feito por 7 cartas topográficas digitalizadas, e com auxílio de GPS de navegação utilizado em campo. Foram coletados dados como altitude, estradas distâncias parceladas, postos de abastecimento e pontos de interesse (fazendas, granjas, igrejas e capelas, reservas de mata nativa, culturas perenes e silviculturas, linhas de alta tensão e indústrias, entre outros). Esse mapeamento ajudou nas nomenclaturas locais dos Mesoclimas.

Como visto no Mapa 1, foram utilizados dados históricos com 35 anos de medições (1981-2015) em dez estações pluviométricas da Agência Nacional de Águas (ANA) e uma estação climatológica do Instituto Nacional de Meteorologia (INMET) dentro e no entorno do município de Prata (MG). A estação climatológica experimental da Universidade Federal de Uberlândia (UFU), nomeada de Casa Amarela, funcionou dentro da zona urbana de Prata durante os anos de 2002 a 2008 e seus dados foram utilizados como complemento para as interpolações. 


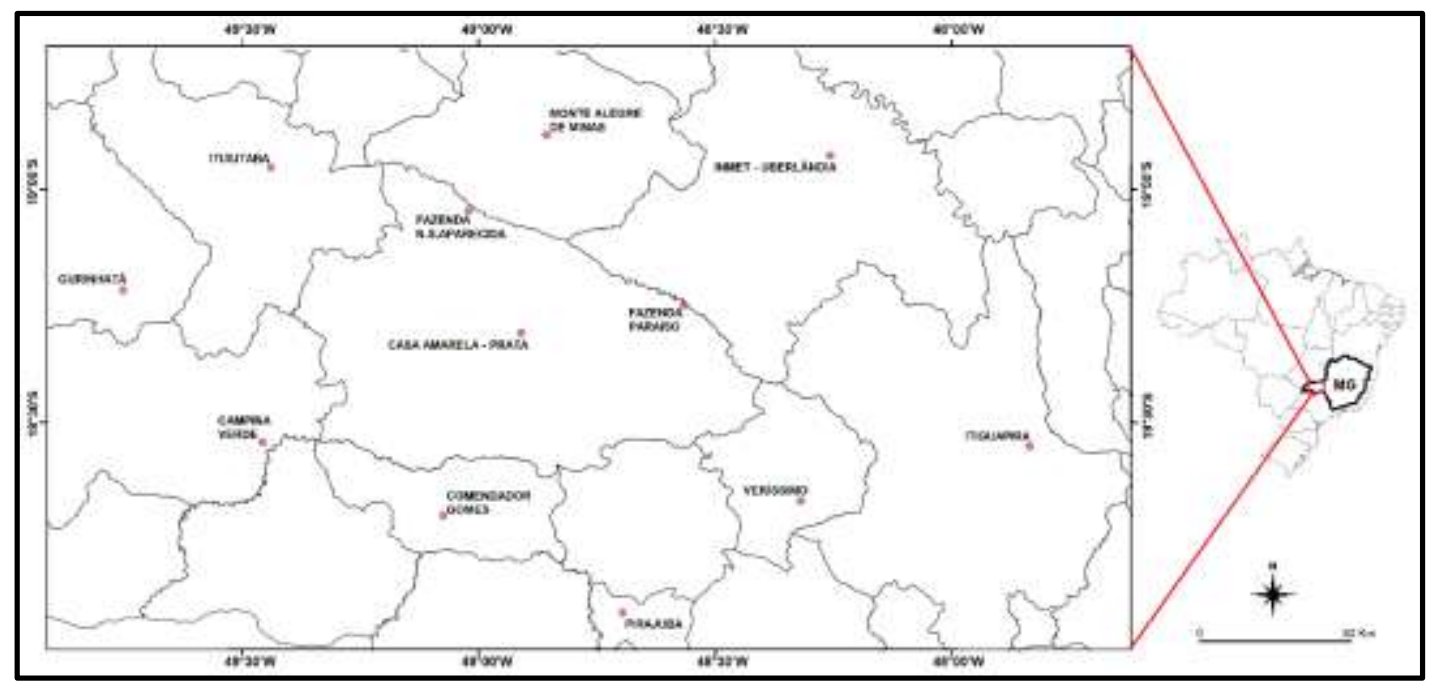

Mapa 1 - Localização das estações pluviométricas do INMET e da ANA.

O algoritmo de temperatura do ar CHELSA (Climatologies at high resolution for the earth's land surface áreas) foi usado para cobrir as áreas com falta de estações meteorológicas. Esse algoritmo é um conjunto de dados climáticos de alta resolução (30 segundos de arco $\sim 1 \mathrm{~km}$ ) para as áreas da superfície terrestre. Foi elaborado por Karger et al (2017) e atualmente é hospedado pelo Instituto Federal Suíço de Pesquisa de Floresta, Neve e Paisagem WSL. Desenvolvido em cooperação com os Departamentos de Geografia das Universidades alemãs de Hamburgo, Zurique e de Göttingen. O conjunto de dados usado pelo CHELSA foi extraído da Reanálise ERA-Interim, que combina resultados de modelagem e recuperação de informações coletadas sobre a superfície e oceanos através de navios, aviões, radiossondas e satélites. Inclui a temperatura média mensal e padrões de precipitação para o período de tempo de 1979-2013. A temperatura média diária deriva de dados sinóticos de seis em seis horas, melhorando substancialmente o desempenho da previsão, especialmente no Hemisfério Sul (Rocha et al, 2016). A metodologia de estimativa da temperatura do ar do algoritmo tem uma correlação direta com as imagens SRTM, derivando em mapas mais próximos da realidade, onde as isotermas acompanham as curvas de nível do terreno. Portanto, para Novais (2019), o padrão de distribuição de temperatura na atmosfera livre pode ser considerado diretamente ao tipo de elevação altimétrica na localidade especifica estudada.

\section{RESULTADOS E DISCUSSÃo}

Para a determinação das unidades climáticas de Prata (MG) primeiro devemos entender as condições que propiciam essa divisão, como a influência do relevo, temperatura do ar, precipitação pluviométrica e o balanço hídrico climatológico. 
Inserido na unidade de relevo da Bacia Sedimentar do Paraná, o município possui planaltos sedimentares medianamente dissecados na maior parte (BACCARO et al, 1991). Os relevos residuais se encontram a oeste, no divisor de águas dos rios Paranaíba e Grande, onde as serras com topos planos e escarpas íngremes se destacam na paisagem juntamente com seus pontiagudos morros testemunhos. A planície fluvial do Tijuco-Cabaçal, juntamente com as formações tabulares de cimeira, correspondente ao chapadão do Prata, estão presentes no leste do município (Mapa 2).

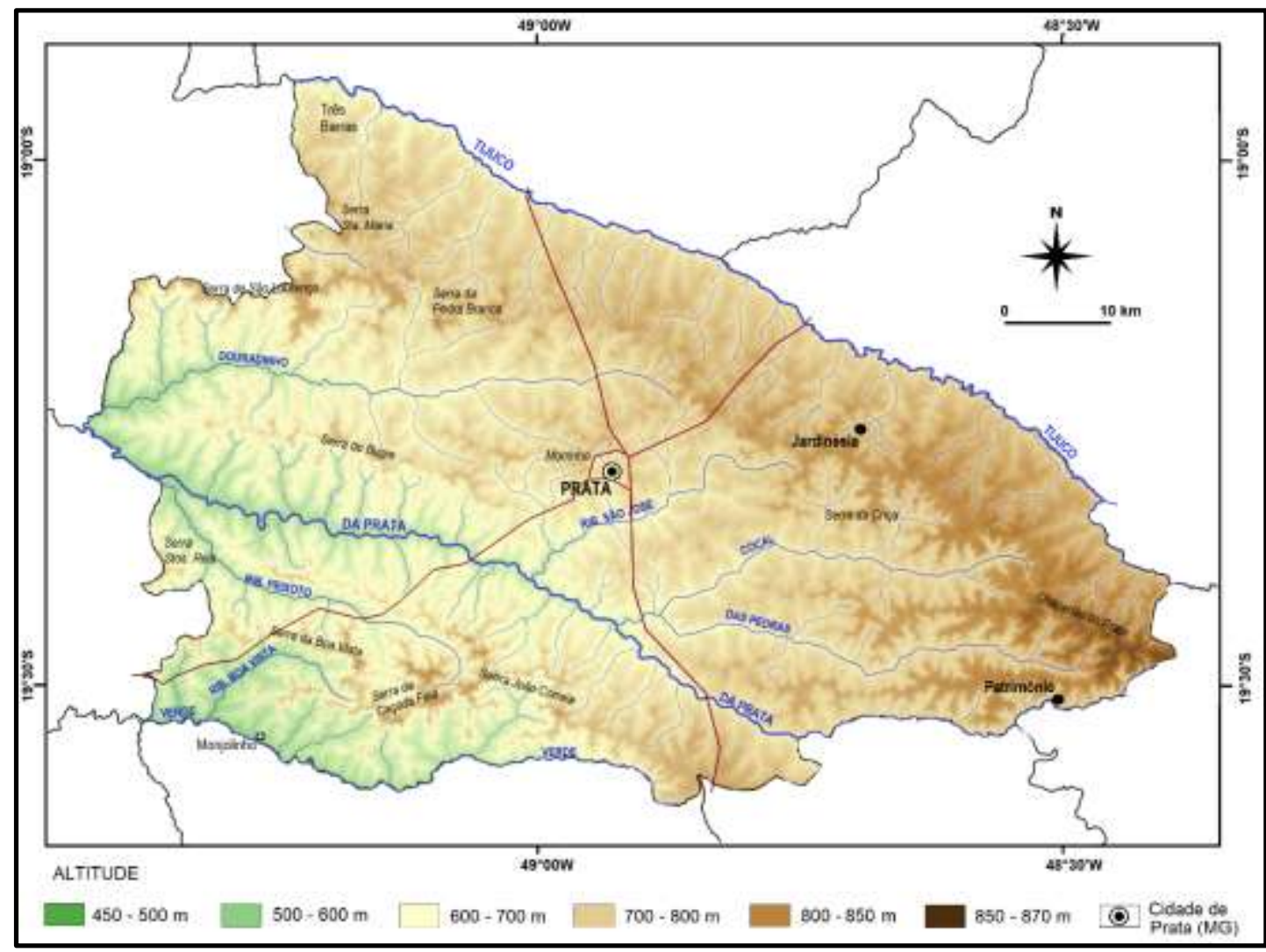

Mapa 2 - Mapa Físico do município de Prata (MG).

Essas formações do relevo e as variações na altitude que vão de 490 a 870 metros, provocam uma diferença no gradiente adiabático que irá auxiliar na delimitação das menores hierarquias da classificação climática aplicada nesse trabalho.

A temperatura média do ar no mês mais frio (TMMMF) é o elemento que separa os Climas Zonais e muitos Domínios Climáticos nesse sistema de classificação. No município de Prata, a TMMMF ocorre no mês de junho e é mostrada a partir do modelo do algoritmo CHELSA, com valores que vão desde os $18,9^{\circ} \mathrm{C}$ no alto do chapadão localizado a sudeste (limite com o município de Veríssimo) até o fundo do vale do rio da Prata (limite com o município de Campina Verde), no oeste do município, com valores que chegam a $21,1^{\circ} \mathrm{C}$ (Mapa 3). O município não registra valores de TMMMF que o faz pertencer ao Clima Zonal Tórrido (TMMMF acima de $22,5^{\circ} \mathrm{C}$ ), nem tão pouco ao Clima Zonal Moderado (TMMMF entre $0^{\circ}$ e $15^{\circ} \mathrm{C}$ ), sendo todo o seu território dentro do Clima Zonal Quente (entre $15^{\circ}$ e $22,5^{\circ} \mathrm{C}$ ). Em termos de Domínio Climático, o 
município também não possui áreas de domínio Tropical Ameno, pois suas TMMMF estão todas acima de $18^{\circ} \mathrm{C}$. Como visto no Mapa 3, o gradiente térmico dentro do município não é tão grande $\left(1,5^{\circ} \mathrm{C}\right)$, mas proporciona uma diferença na ETP, fundamental para a determinação da quantidade de meses secos.

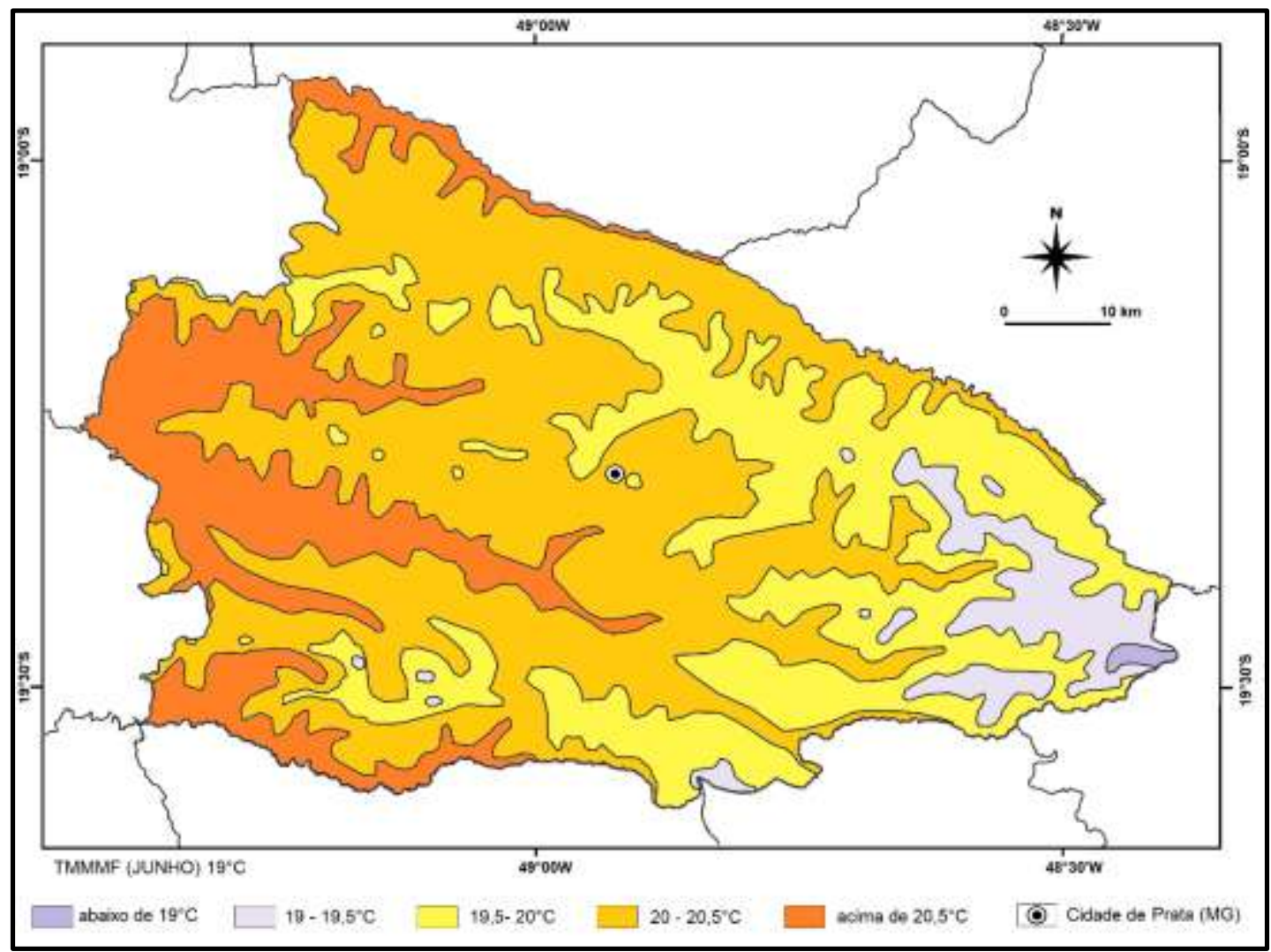

Mapa 3 - Temperatura Média do mês mais frio (TMMMF) no município de Prata (MG).Fonte: CHELSA.

Em termos de precipitação média anual, o município apresenta cinco classes de quantidade de chuva. A área com os maiores valores (acima de 1550 $\mathrm{mm}$ ) aparece no leste, inclui o distrito de Jardinésia e a parte mais alta do município. Nessa área, o maior valor de chuva ajuda a aumentar a quantidade de água que entra no sistema, influenciando também na quantidade de meses secos. A segunda área com maior precipitação pluviométrica abrange a maior parte do município, onde está inserido a zona urbana, tendo valores entre 1500 e $1550 \mathrm{~mm}$. Os menores valores de precipitação ficaram abaixo de $1400 \mathrm{~mm}$, e aparecem no norte, desde a foz do Rio Douradinho até as Três Barras (Mapa 4). 


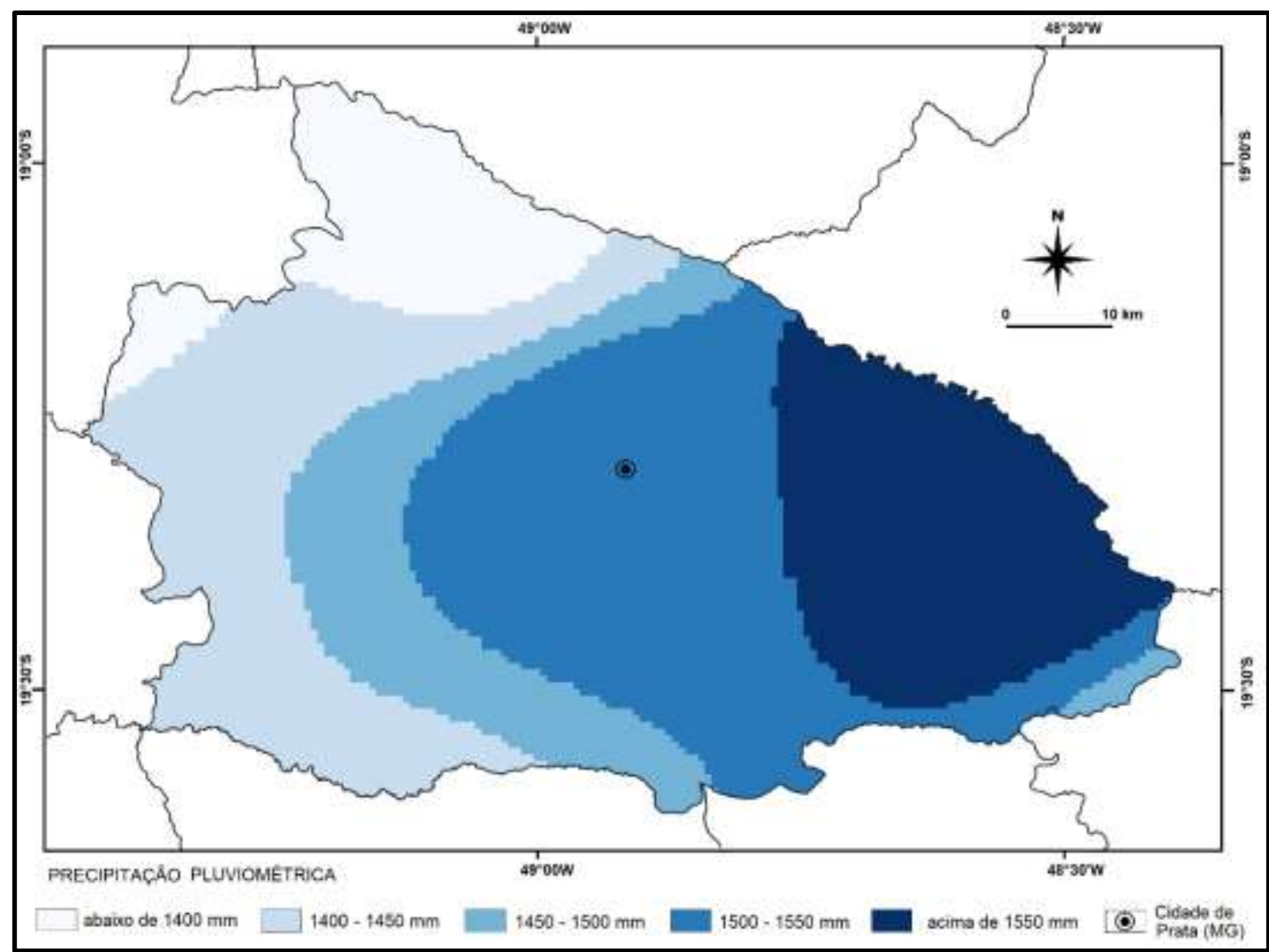

Mapa 4 - Precipitação pluviométrica média anual no município de Prata (MG). Fonte: ANA e INMET.

O balanço hídrico anual nesse trabalho é representado pelo excedente e o déficit hídrico. Esses parâmetros são essenciais para se ter um maior detalhamento de entrada e saída de água no sistema solo-planta-atmosfera. Se temos um excesso de água no sistema, isso irá gerar um escoamento superficial e uma drenagem profunda para o lençol freático, favorecendo, por exemplo, um crescimento máximo das plantas. Agora, com um maior déficit hídrico, há uma restrição no crescimento das plantas e uma diminuição da vazão da drenagem superficial, significando que o solo está potencialmente seco. Em termos de excedente, o município apresenta valores entre 495 e $570 \mathrm{~mm}$. Sendo os maiores excedentes no leste e sul do município (acima de $550 \mathrm{~mm}$ ) e os menores excedentes no extremo oeste (abaixo de $350 \mathrm{~mm}$ ). O déficit hídrico anual oscila entre 180 e $240 \mathrm{~mm}$, onde o maior déficit também é registrado no extremo oeste do município (acima de $275 \mathrm{~mm}$ ) e o menor no centro-nordeste com menos de $225 \mathrm{~mm}$ (Mapa 5). 


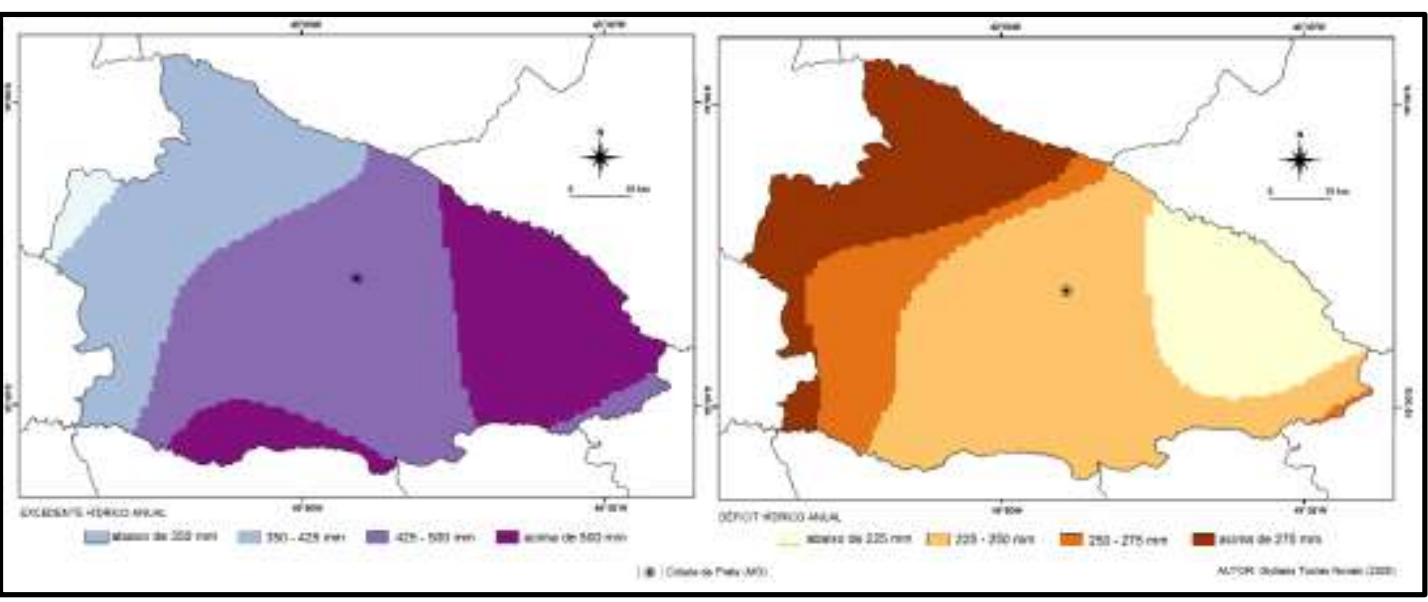

Mapa 5 - Balanço Hídrico Anual no município de Prata (MG).

A quantidade de meses secos é a diferença entre a precipitação pluviométrica e a ETP (que é influenciada principalmente pelos valores de temperatura média mensal), averiguadas na planilha de balanço hídrico. Os locais de menor altitude e maior temperatura favorecem a maior quantidade de meses secos. Já os locais onde a temperatura média mensal é mais baixa e também onde a precipitação é maior, os valores ajudam a aumentar o excedente hídrico mensal, diminuindo os meses onde a evapotranspiração é maior (Novais et al 2018). Nos vales dos rios da Prata, Tijuco (baixo curso no município), Verde, Douradinho, Cocal e das Pedras, a quantidade de meses secos atinge os sete. Já no chapadão que vai do centro-norte a leste do município, e nos relevos residuais do oeste, os meses secos são seis.

A partir dos dados mostrados anteriormente foram identificados as unidades climáticas do município de Prata (MG), mostrados no Mapa 6. Todos os subtipos climáticos apresentados a seguir pertencem a Zona Climática Quente, ao Clima Zonal Quente e ao Domínio Climático Tropical, com influência das Zonas de Convergência de Umidade e do Atlântico Sul (ZCOUs e ZCAS) no período úmido (de novembro a março) e da Alta Subtropical do Atlântico Sul (ASAS) no período seco (que varia de acordo com o subdomínio climático). 0 Subdomínio Climático Semisseco e o Tipo Climático Meridional também é comum a todos os subtipos, e de acordo com Novais (2019), com incursões de frentes frias periódicas (15 por ano) e rara possibilidade de formação de geadas (uma a cada 6 anos em média). Por estar localizado dentro do Domínio Tropical e com pouca diferença de subdomínios e tipos o município de Prata possui pouca diferenciação nas primeiras hierarquias climáticas.

Os subtipos climáticos são em número de três, seguindo a metodologia de Novais et al (2018). Foram criados 34 Mesoclimas a partir da delimitação geomorfológica, que abrange aspectos do relevo como fundo de vales, planaltos e locais cercados por serras; bem como áreas com influência de vegetação nativa e da zona urbana (sendo este aproveitando os dados do Posto Climatológico da Casa Amarela, que funcionou na cidade). Essa última hierarquia (Mesoclimas) da classificação climática de Novais será exposta em forma de um quadro.

Para um melhor entendimento da Classificação Climática de Novais, sugerimos a leitura de trabalhos específicos do autor, como Novais (2017), 
Novais et al (2018), Novais (2019) e Nascimento \& Novais (2020), em que as primeiras hierarquias climáticas são mais detalhadas, mostrando todos os Domínios, Subdomínios e Tipos Climáticos existentes, e não somente os que estão nesse trabalho.

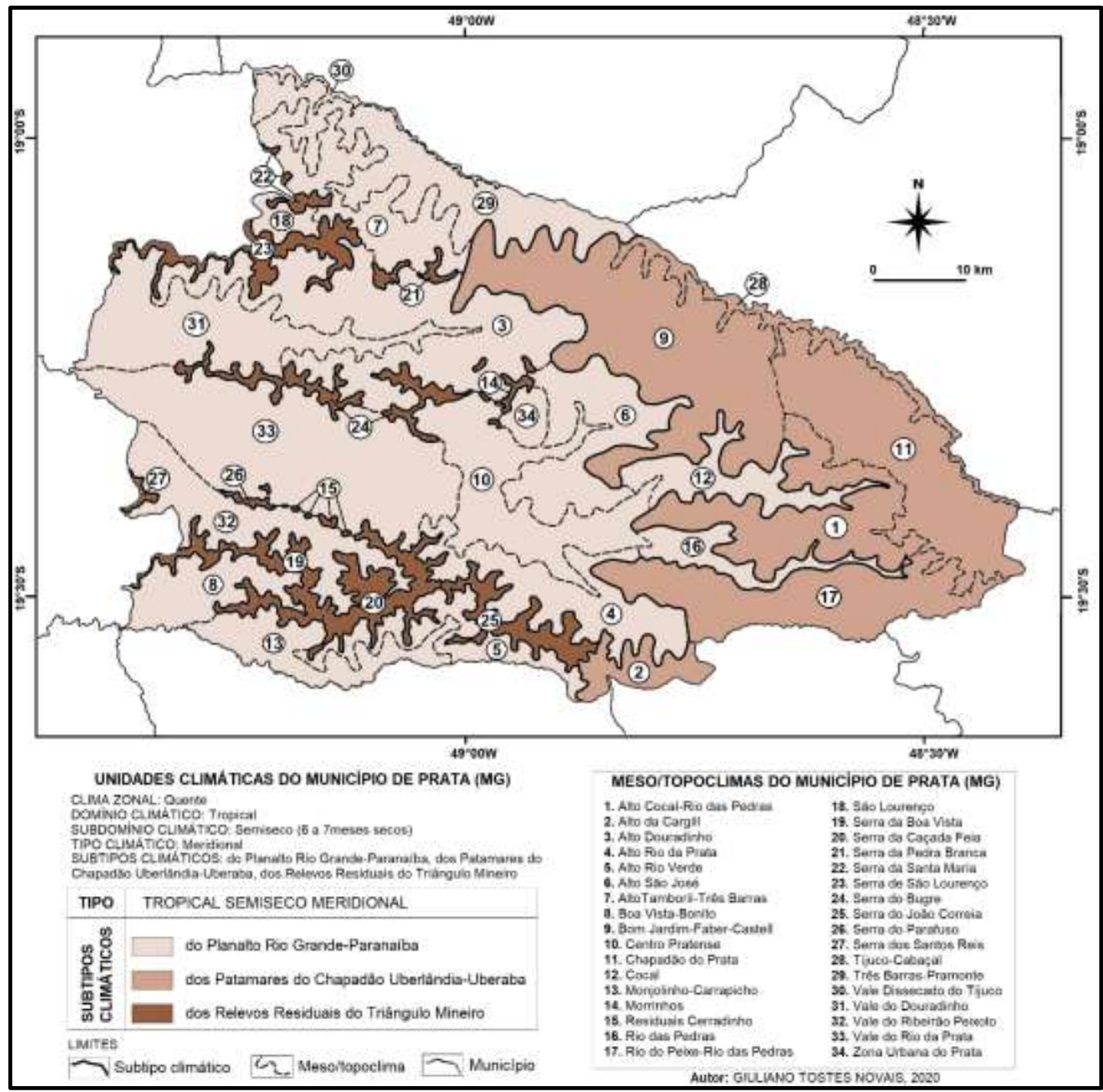

Mapa 6 - Unidades Climáticas do município de Prata (MG). Tropical semisseco meridional, do Planalto Rio Grande-Paranaíba

TROPICAL SEMISSECO MERIDIONAL, DO PLANALTO RIO GRANDE-PARANAÍBA Unidade climática que abrange a maior parte do município de Prata, englobando todo o médio e baixo vales dos rios Tijuco, Douradinho, da Prata e Verde, incluindo seus principais afluentes. Compreende a zona urbana, mais o povoado de Monjolinho e a comunidade das Três Barras. É uma continuação do subtipo que predomina no Pontal do Triângulo. Possui relevo medianamente dissecado com altimetrias que variam de 490 a 720 metros.

Seu Subdomínio é o Semiseco, com sete meses secos (abril a outubro). A TMMMF (junho) varia de $20^{\circ}$ a $21,1^{\circ} \mathrm{C}$, com precipitação pluviométrica anual 
entre 1380 e $1620 \mathrm{~mm}$. O excedente hídrico anual fica entre 320 e $570 \mathrm{~mm}$ e o déficit hídrico anual entre 210 e $280 \mathrm{~mm}$.

\section{TROPICAL SEMISSECO MERIDIONAL, DOS PATAMARES DO CHAPADÃO UBERLÂNDIA-UBERABA}

A influência das terras mais altas do leste e sul do município faz-se sentir na menor ETP, tornando a quantidade de meses secos menor. Faz a transição dos baixos vales dos rios Grande-Paranaíba para as áreas mais elevadas do chapadão de Uberlândia e Uberaba. Abrange os distritos de Jardinésia e Patrimônio. Possui formações tabulares de cimeira, correspondente ao grande chapadão do Prata, com altimetrias variando de 640 a 870 metros.

Seu Subdomínio é o Semiseco, com seis meses secos (abril a setembro). A TMMMF acontece em junho, e varia de $18,9^{\circ}$ a $20,5^{\circ} \mathrm{C}$, com precipitação pluviométrica anual de 1490 a $1630 \mathrm{~mm}$ (região de maior pluviosidade média da área de estudo). O excedente hídrico anual fica entre 490 e $580 \mathrm{~mm}$ e o déficit hídrico anual entre 205 e $240 \mathrm{~mm}$.

\section{TROPICAL SEMISSECO MERIDIONAL, DOS RELEVOS RESIDUAIS DO TRIÂNGULO MINEIRO}

Esse subtipo climático engloba as áreas dos relevos residuais típicos do oeste do Triângulo Mineiro. Esse relevo destaca-se na paisagem com morros testemunhos e serras escarpadas, que influenciam na quantidade de umidade, pois a ETP é menor, juntamente com a quantidade de meses secos. Aparecem no centro do município nos arredores da zona urbana e seguem a linha de cumeada até o limite com os municípios de Campina Verde e Ituiutaba. As altimetrias variam de 650 a 780 metros.

Seu Subdomínio é o Semiseco, com seis meses secos (abril a setembro). A TMMMF (junho) varia de $19,4^{\circ}$ a $20,5^{\circ} \mathrm{C}$, com precipitação pluviométrica anual de 1400 a $1530 \mathrm{~mm}$. O excedente hídrico anual fica entre 320 e $520 \mathrm{~mm}$ e o déficit hídrico anual entre 220 e $300 \mathrm{~mm}$.

\section{MESOCLIMA DA ZONA URBANA DE PRATA (MG)}

Exemplo de mesoclima delimitado pelos divisores de água que cercam a área da zona urbana de Prata, desde a entrada da cidade na BR 153 passando pelo anel viário e indo até a base do Morrinho (Serra Seio de Moça). A delimitação deve-se pela influência urbana em sua bacia hidrográfica, gerando padrões diferentes de temperatura, escoamento superficial e subsuperficial (impermeabilização do solo), poluição atmosférica e retirada de vegetação natural. Essa unidade climática está inserida dentro do subtipo Tropical Semiseco Meridional, do Planalto Rio Grande-Paranaíba. O relevo característico da cidade é o medianamente dissecado, com variação altimétrica entre 600 e 700 metros.

Pertence ao Clima Zonal Quente, com incidência solar direta (Sol no Zênite $=0^{\circ}$ ) no início de Novembro e meio de Janeiro, e com o Sol na máxima distância zenital no final de junho (43 Norte). O Domínio Climático é o Tropical, 
com influência das ZCOUs e ZCAS no período úmido e da ASAS no período seco. O Tipo Climático é o Meridional, com incursões de 15 frentes frias por ano, e com possibilidade de formação de uma geada a cada 6 anos em média. Seu Subdomínio é o Semiseco, com sete meses secos (abril a outubro).

Aproveitando os dados coletados durante os seis anos de funcionamento do Posto Climatológico da Casa Amarela (zona urbana), e interpolando os dados dos postos vizinhos, temos um maior detalhamento dos elementos climáticos. A Temperatura Média Anual é de $23,8^{\circ} \mathrm{C}$, com máximas absolutas de $40^{\circ} \mathrm{C}$ em outubro e mínimas absolutas de $7^{\circ} \mathrm{C}$ em junho. A TMMMF (junho) é de $20,1^{\circ} \mathrm{C}$. A precipitação pluviométrica anual de $1535 \mathrm{~mm}$, sendo os meses mais chuvosos Janeiro, Dezembro e Fevereiro. A precipitação máxima em 24 horas acontece geralmente nos meses de março, dezembro ou janeiro, e tem uma média de 86 $\mathrm{mm}$, o que pode ocasionar inundações nos principais córregos do entorno da cidade. O excedente hídrico anual é de $455 \mathrm{~mm}$ e o déficit hídrico anual de 229 $\mathrm{mm}$.

OS OUTROS MESOCLIMAS DO MUNICÍPIO DE PRATA (MG)

A seguir, serão apresentados no Quadro 2, dados geoclimáticos de todos os 34 mesoclimas delimitados dentro do município de Prata. Mostrando características do relevo, uso do solo, altitude e valores de TMMMF, precipitação pluviométrica, quantidade de meses secos, excedente e déficit hídrico além do subtipo climático em que estão inseridos. 
Quadro 2 - Características geoclimáticas dos Meso/Topoclimas do município de Prata (MG).

\begin{tabular}{|c|c|c|c|c|c|c|c|c|c|}
\hline Meso/Topoclima & Relevo & Uso do Solo & $\begin{array}{l}\text { Altitude } \\
\text { (m) }\end{array}$ & $\begin{array}{l}\text { TMMMF } \\
\left({ }^{\circ} \mathrm{C}\right)\end{array}$ & $\begin{array}{l}\text { Precipitação } \\
\text { (mm) }\end{array}$ & \begin{tabular}{|l}
$\begin{array}{l}\text { Excedente } \\
(\mathrm{mm})\end{array}$ \\
\end{tabular} & $\begin{array}{l}\text { Déficit } \\
(\mathrm{mm})\end{array}$ & \begin{tabular}{|l|} 
Meses \\
Secos
\end{tabular} & $\begin{array}{l}\text { Subtipo } \\
\text { Climático }\end{array}$ \\
\hline Alto Cocal - Rio das Pedras & $\mathrm{PL}, \mathrm{S}$ & $\mathrm{SI}, \mathrm{PA}, \mathrm{M}$ & $680-800$ & $19,5-20,2$ & $1545-1600$ & $480-555$ & $215-225$ & 6 & PCU \\
\hline Alto da Cargill & $\mathrm{PL}$ & AG, PA & $640-750$ & $19,5-20,1$ & \begin{tabular}{|l|}
$1480-1525$ \\
\end{tabular} & $490-510$ & $235-245$ & 6 & PCU \\
\hline Alto Douradinho & $\mathrm{PL}, \mathrm{VC}, \mathrm{S}, \mathrm{MT}$ & PA, SI & $600-730$ & $20,0-20,8$ & $1400-1535$ & $390-455$ & $230-300$ & 7 & PRP \\
\hline Alto Rio da Prata & $\mathrm{VA}, \mathrm{PL}$ & $\mathrm{PA}, \mathrm{AG}, \mathrm{M}$ & $610-710$ & $19,8-20,4$ & $1485-1535$ & $460-495$ & $230-240$ & 7 & PRP \\
\hline Alto Rio Verde & $\mathrm{PL}, \mathrm{VC}, \mathrm{VA}$ & $\mathrm{PA}, \mathrm{AG}, \mathrm{M}$ & $555-710$ & $19,9-20,6$ & $1435-1490$ & $485-530$ & $235-245$ & 7 & PRP \\
\hline Alto São José & $\mathrm{PL}, \mathrm{S}$ & AG, SI, PA, M & $620-720$ & $20,0-20,4$ & $1530-1565$ & $450-500$ & $225-230$ & 7 & PRP \\
\hline Alto Tamboril - Três Barras & $\mathrm{PL}, \mathrm{S}$ & SI, PA & $635-730$ & $20,0-20,6$ & $1390-1405$ & $370-400$ & $285-305$ & 7 & PRP \\
\hline Boa Vista - Bonito & $\mathrm{VC}, \mathrm{S}, \mathrm{MT}, \mathrm{VA}$ & $\mathrm{PA}, \mathrm{M}$ & $490-610$ & $19,9-20,9$ & $1415-1450$ & $350-500$ & $245-280$ & 7 & PRP \\
\hline Bom Jardim - Faber Castell & $\mathrm{PL}, \mathrm{S}$ & PA, SI, I & $655-785$ & $19,5-20,2$ & $1390-1625$ & $385-575$ & $210-305$ & 6 & PCU \\
\hline Centro Pratense & $\mathrm{VA}, \mathrm{VC}, \mathrm{PL}, \mathrm{S}$ & $\mathrm{PA}, \mathrm{SI}, \mathrm{AG}, \mathrm{M}, \mathrm{I}$ & $555-695$ & $20,0-20,7$ & $1520-1540$ & $455-475$ & $225-235$ & 7 & PRP \\
\hline Chapadão do Prata & $\mathrm{PL}$ & $\mathrm{PA}, \mathrm{SI}, \mathrm{I}, \mathrm{M}$ & $680-870$ & $18,9-20,1$ & $1480-1630$ & $475-575$ & $210-250$ & 6 & PCU \\
\hline Cocal & VC, S & $\mathrm{PA}, \mathrm{AG}, \mathrm{SI}, \mathrm{M}, \mathrm{I}$ & $615-695$ & $20,0-20,3$ & $1535-1625$ & $460-575$ & $210-230$ & 7 & PRP \\
\hline Monjolinho - Carrapicho & $\mathrm{VA}, \mathrm{VC}, \mathrm{S}$ & $\mathrm{PA}, \mathrm{M}$ & $500-600$ & $20,2-20,8$ & $1420-1460$ & $385-530$ & $240-275$ & 7 & PRP \\
\hline Morrinhos & MT, S & M, PA & $690-790$ & $19,7-20,2$ & $1530-1535$ & $450-455$ & $230-235$ & 6 & RRT \\
\hline Residuais Cerradinho & MT, S & $M$ & $630-725$ & $20,0-20,4$ & $1460-1480$ & $440-465$ & $245-255$ & 6 & RRT \\
\hline Rio das Pedras & VC, S & PA, M & $620-710$ & $20,0-20,3$ & $1530-1595$ & $465-550$ & $215-230$ & 7 & PRP \\
\hline Rio do Peixe - Rio das Pedras & $\mathrm{PL}, \mathrm{S}, \mathrm{VA}$ & PA, SI, M & $630-815$ & $19,3-20,2$ & $1460-1575$ & $465-540$ & $220-255$ & 6 & PCU \\
\hline São Lourenço & VC & $\mathrm{PA}, \mathrm{M}$ & $615-695$ & $20,0-20,6$ & $1390-1400$ & $375-385$ & $295-300$ & 7 & PRP \\
\hline Serra da Boa Vista & $\mathrm{S}$ & $M, P A$ & $610-765$ & $19,5-20,5$ & \begin{tabular}{|l|}
$1425-1465$ \\
\end{tabular} & $420-520$ & $245-265$ & 6 & RRT \\
\hline Serra da Caçada Feia & $\mathrm{S}$ & $\mathrm{M}, \mathrm{PA}$ & $630-775$ & $19,4-20,4$ & $1440-1520$ & $475-525$ & $235-245$ & 6 & RRT \\
\hline Serra da Pedra Branca & $\mathrm{S}, \mathrm{PL}$ & $\mathrm{M}, \mathrm{PA}, \mathrm{SI}$ & $715-795$ & $19,7-20,1$ & $1400-1420$ & $380-400$ & $285-305$ & 6 & RRT \\
\hline Serra da Santa Maria & $\mathrm{S}, \mathrm{PL}$ & $M, P A, S I$ & $700-770$ & $19,8-20,3$ & $1385-1390$ & $370-380$ & $295-305$ & 6 & RRT \\
\hline Serra de São Lourenço & $\mathrm{S}, \mathrm{PL}$ & M, SI, PA & $650-765$ & $19,8-20,5$ & $1380-1415$ & $310-395$ & $280-300$ & 6 & RRT \\
\hline Serra do Bugre & $\mathrm{S}$ & $\mathrm{M}, \mathrm{SI}, \mathrm{PA}$ & $610-735$ & $19,9-20,5$ & $1420-1535$ & $370-445$ & $230-275$ & 6 & RRT \\
\hline Serra do João Correia & $\mathrm{S}$ & $\mathrm{M}, \mathrm{PA}$ & $630-775$ & $19,4-20,3$ & $1450-1515$ & $470-520$ & $235-240$ & 6 & RRT \\
\hline Serra do Parafuso & $\mathrm{s}$ & M & $615-700$ & $20,1-20,6$ & $1435-1460$ & $400-440$ & $255-265$ & 6 & RRT \\
\hline Serra dos Santos Reis & S & $\mathrm{M}, \mathrm{PA}$ & $625-710$ & $20,0-20,3$ & $1415-1420$ & $360-365$ & $275-280$ & 6 & RRT \\
\hline Tijuco - Cabaçal & $\mathrm{VA}, \mathrm{PN}, \mathrm{PL}, \mathrm{VE}$ & $\mathrm{PA}, \mathrm{I}, \mathrm{AG}, \mathrm{M}$ & $615-720$ & $19,8-20,5$ & $1490-1635$ & $465-580$ & $205-250$ & 6 & PCU \\
\hline Três Barras - Pramonte & VE, PL & $\mathrm{PA}, \mathrm{SI}, \mathrm{AG}, \mathrm{I}, \mathrm{M}$ & $595-710$ & $20,0-21,0$ & $1385-1490$ & $365-475$ & $245-310$ & 7 & PRP \\
\hline Vale Dissecado do Tijuco & VE & M, PA & $545-605$ & $20,5-21,1$ & $1385-1390$ & $365-385$ & $290-310$ & 7 & PRP \\
\hline Vale do Douradinho & $\mathrm{VA}, \mathrm{PL}, \mathrm{VC}$ & $\mathrm{PA}, \mathrm{SI}, \mathrm{AG}, \mathrm{M}$ & $510-620$ & $20,4-21,1$ & $1380-1525$ & $315-450$ & $235-280$ & 7 & PRP \\
\hline Vale do Ribeirão Peixoto & $\mathrm{VA}, \mathrm{VC}, \mathrm{S}, \mathrm{MT}$ & $\mathrm{PA}, \mathrm{M}$ & $525-630$ & $20,2-21,0$ & $1420-1485$ & $365-510$ & $240-275$ & 7 & PRP \\
\hline Vale do Rio da Prata & $\mathrm{VA}, \mathrm{PL}, \mathrm{VC}$ & $\mathrm{PA}, \mathrm{SI}, \mathrm{AG}, \mathrm{I}, \mathrm{M}$ & $505-695$ & $20,0-21,2$ & $1405-1530$ & $345-470$ & $230-280$ & 7 & PRP \\
\hline Zona Urbana do Prata & $\mathrm{VE}, \mathrm{PL}, \mathrm{M}$ & $\mathrm{ZU}, \mathrm{I}, \mathrm{PA}$ & $600-700$ & $20,0-20,4$ & $1530-1535$ & $450-455$ & $225-230$ & $6-7$ & PRP \\
\hline
\end{tabular}

\section{SIGLAS}

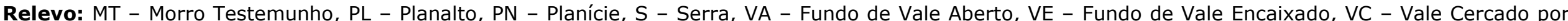

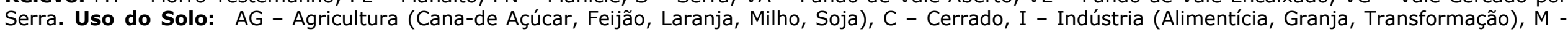

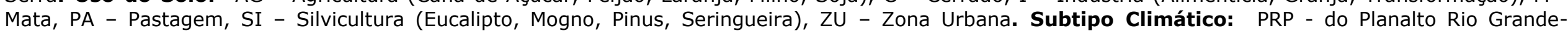

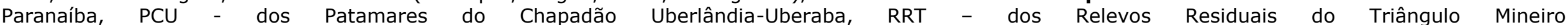




\section{CONSIDERAÇÕES FINAIS}

Esse modelo de classificação climática adotado para identificar as unidades climáticas do município de Prata (MG) fornece importantes contribuições para novos estudos regionais. Os subtipos e os meso/topoclimas delimitados, que fazem parte das menores hierarquias climáticas, conseguem mostrar mais detalhes da climatologia, contribuindo para as atividades antrópicas que estudam o meio ambiente e a produção agropecuária.

A determinação das unidades climáticas nesse trabalho mostrou a importância da TMMMF, da precipitação pluviométrica e da quantidade de meses secos, controlados pelos sistemas atmosféricos. O componente estrutural geomorfológico, fato diretamente ligado à dinâmica climática atual e pretérita, serviu para demarcar as menores unidades.

A instalação do Posto Climatológico da Casa Amarela nos revela que a zona urbana possui uma temperatura média do mês mais frio (TMMMF) acima de $20^{\circ} \mathrm{C}$, a quantidade média de chuva durante o ano fica em $1535 \mathrm{~mm}$, sendo os meses de Janeiro, Dezembro e Fevereiro os mais chuvosos. A quantidade de meses secos ficou em sete (abril - outubro), que somando aos valores dos elementos climáticos e aos aspectos do relevo torna o clima da cidade Tropical Semiseco meridional, do Planalto Rio Grande-Paranaíba.

Futuramente, para trabalhos mais detalhados a nível mesoclimático, sugerimos a verificação "in loco", com a instalação de estações climatológicas (como feito na zona urbana) em cada unidade climática para coletar dados atmosféricos com maior precisão. Assim poderemos estudar melhor a climatologia local com diferenciações mais significativas.

\section{REFERÊNCIAS}

ARMOND, N.B.; SANT'ANNA NETO, J.L. A Climatologia dos Geógrafos e a produção científica sobre Classificação Climática: um balanço inicial. XII Simpósio Brasileiro de Climatologia Geográfica. Goiânia, 2016.

BACCARO, C.A.D.; FERREIRA, I.V.; ROCHA, M.R.; RODRIGUES, S.C. Mapa geomorfológico do Triângulo Mineiro: uma abordagem morfoestruturalescultural. In: Revista Sociedade \& Natureza. Uberlândia, 13 (25): 115-127, 2001.

BARRY, R.G., CHORLEY, R J. Atmosfera, Tempo e Clima. 9a edição, Porto Alegre; Bookman, 2013 (Tradução de Ronaldo CAtaldo Costa), 512p.

BRUCHMANN, E. T. Mesoclimatologia. Série 47 (1). Univ. Nacional de Tucuman, 1978.

CAVALCANTI, I.F.A.; FERREIRA, N.J.; DA SILVA, M.G.A.; DIAS, M.A.F.S. Tempo e clima no Brasil. São Paulo: Oficina de Textos, 2009.

JARDIM, C.H. Aspectos Multiescalares e Sistêmicos da Análise Climatológica. Revista Geografias,2015. p.40-52.

JESUS, E. F. R. Algumas reflexões teórico-conceituais na climatologia geográfica em mesoescala: uma proposta de investigação. GeoTextos, vol. 4, n. 1 e 2, 2008. p.165-187. 
KARGER, D.N., CONRAD, O., BÖHNER, J., KAWOHL, T., KREFT, H., SORIAAUZA, R.W., ZIMMERMANN, N.E., LINDER, H.P., KESSLER, M. Dados de Climatologia em alta resolução para as áreas terrestres. In: Dryad Digital.Repository. 2017. https://doi.org/10.5061/dryad.kd1d4.

MILANESI, M.A. Identificação de unidades climáticas na Ilha de São Sebastião. Tese de doutorado apresentada ao Programa de Pós-Graduação em Geografia da Faculdade de Filosofia, Letras e Ciências Humanas da Universidade de São Paulo. 2016.

MONTEIRO, C. A. A Dinâmica Climática e as Chuvas no Estado de São Paulo. Instituto de Geografia - USP, São Paulo. 1973.

NASCIMENTO, D.T.F.; NOVAIS, G.T. Clima do Cerrado: dinâmica atmosférica e características, variabilidades e tipologias climáticas. Eliséé - Revista de Geografia da UEG. vol.9, n.2. 2020.

NIMER, E. Ensaio de um novo método de classificação climática: contribuição à climatologia intertropical e subtropical, especialmente do Brasil. Boletim de Geografia. Rio de Janeiro, v. 31, n.277: pp.141-153, mar/abril, 1972.

NÓBREGA, R.S. Um pensamento crítico sobre classificações climáticas: de Köppen até Strahler. Revista Brasileira de geografia física. Recife, 2010.

NOVAIS, G.T. Classificação Climática aplicada ao Bioma Cerrado. Tese de doutorado apresentada ao Instituto de Geografia da Universidade Federal de Uberlândia. 2019. https://dx.doi.org/10.14393/ufu.te.2019.2199

NOVAIS, G.T. Distribuição média dos Climas Zonais no Globo: estudos preliminares de uma nova classificação climática. Revista Brasileira de Geografia Física, Recife, v.10, n.5, p. 2017. https://doi.org/10.26848/rbgf.v.10.5.p1614-1623

NOVAIS, G.T. Guia do Município 2014 - Prata (MG). 20p.: il. color; 30cm. ISBN: 978-85-916149-0-5. Uberlândia, 2013.

NOVAIS, G.T. BRITO, J.L.S., SANCHES, F.O. Unidades climáticas do Triângulo Mineiro/Alto Paranaíba-MG. Revista Brasileira de Climatologia, Curitiba, v.23, p. 223-243, jul/dez 2018. https://doi.org/10.5380/abclima.v23i0.58520

PIMENTA, J.S. Caracterização climática do município de Formosa (GO). Trabalho de conclusão do curso de Geografia. UEG/Campus Formosa, 2019.

RIBEIRO, A.G. As escalas do clima. Boletim de Geografia Teorética. Rio Claro: V23(4646):288-294, 1993.

REMPP, G. A. A respeito das fronteiras e relações entre Macroclima, Mesoclimas, Microclimas e entre o clima físico e o bioclima. La Meteorologia, França, 1937.

ROCHA, F.B.; ARAVÉQUIA, J.A.; RIBEIRO, B.Z. Estudo de Ciclones e de Padrões de Circulação Atmosférica no Oceano Atlântico Sul Próximo à Costa das Regiões Sul e Sudeste do Brasil Usando Dados da Reanálise do Era-Interim. Revista Brasileira de Meteorologia, vol.31, n.2 São Paulo Abr./Jun 2016. https://doi.org/10.1590/0102778631220140151

ROLIM, G.S. Balanço Hídrico. Aula da disciplina de Agrometeorologia do Departamento de Ciências Exatas. Universidade Estadual Paulista (UNESP/Jaboticabal), 2020. 
SAMPAIO, M.S.; ALVES, M.C.; CARVALHO, L.G.; SANCHES, L. Uso de Sistema de Informação Geográfica para comparar a classificação climática de KoppenGeiger e de Thornthwaite. Anais XV Simpósio Brasileiro de Sensoriamento Remoto - SBSR, Curitiba, p.8858, 2011.

SANT'ANNA NETO, João Lima. Escalas geográficas do clima: mudança, variabilidade e ritmo. In: Margarete C. de Costa Trindade Amorim; João Lima Sant'Anna Neto; Ana Monteiro (org.). Climatologia Urbana e Regional: questões teóricas e estudos de caso. $1^{\text {a }}$ edição. São Paulo: Outras Expressões, 2013.

SENTELHAS, P.C., ROLIM, G.S., BARBIERI, V. Planilhas no ambiente EXCEL TM para os cálculos de balanços hídricos: normal, sequencial, de cultura e de produtividade real e potencial. Revista Brasileira de Agrometeorologia, Santa Maria, v. 6, n.1, p133-137, 1998.

SILVA, A.A.F.; JARDIM, C.H. Unidades Climáticas em Unaí, Noroeste de Minas Gerais-Brasil: proposta preliminar. Geographia Opportuno Tempore, Londrina, v. 5, n. 1, p. 10 - 26, 2019.

TARIFA, J.R; AZEVEDO, T.R. Os climas na cidade de São Paulo: teoria e prática. Laboratório de Climatologia. Faculdade de Filosofia, Letras e Ciências Humanas. Universidade de São Paulo, 2001. 199p. GEOUSP - Coleção Novos Caminhos, 4.

THORNTHWAITE, C.W.; MATHER, J.R. The water balance. Centerton, NJ: Drexel Institute of Technology - Laboratory of Climatology, 1955. 104p.

VIANELLO, R. L.; ALVES, A. R. Meteorologia básica e aplicações. Viçosa: Imprensa Universitária/UFV, 1991. 449 p 